\title{
Does Successful Use of Digital Learning Materials Predict Teachers' Intention to Use Them Again in the Future?
}

Karel Kreijns, Marjan Vermeulen, Hans van Buuren, and Frederik Van Acker

Open University of the Netherlands

\begin{abstract}
Do perceptions of success in using digital learning materials (DLMs) regularly (i.e., several times a week) strengthen (or weaken) teachers' behavioural intentions to use DLMs again? And which psychological factors have a relationship with the intention to use DLMs again? These questions are important in light of stimulating teacher's use of DLMs. To answer this question, teacher "flows" were analysed using crosstabs and multinomial logistic regression. These flows visualize how teachers go from a certain degree of perceived success to a certain strength of behavioural intention. Second, Hayes (2013) process method and structured equation modeling (SEM) techniques were applied to determine the mediating role of attitude, perceived norm, and perceived behavioural control of perceived success on the behavioural intention. The results suggested that the teachers' strength in behavioural intention was in accordance with their perceived success for the case that their self-prediction was positive but that this strength became weaker when teachers' self-prediction was negative. Attitude and perceived norm mediated the effects only when self-prediction was positive whereas perceived behaviour control did this in both cases. Also, there was a direct effect between perceived success and behavioural intention. It is important that teachers get a chance to experience success with the use of DLMs, enabled either by school leaders (regarding in-service teachers) or by teacher training institutions (regarding pre-service teachers). Only then we will see teachers' willingness to use DLMs on a regular basis to grow.
\end{abstract}

Keywords: self-prediction to use digital learning materials, teachers' use of digital learning materials, willingness to use digital learning materials

\section{Introduction}

The Wikiwijs initiative launched by the Dutch Ministry of Education, Culture and Science in 2009 aimed to encourage teachers' use of digital learning materials (DLMs) in their educational practices. Previous experience with information and communication (ICT) tools showed that, although the availability of ICT tools in most schools has increased significantly in recent years, this has not lead to more use of these tools (Tondeur, Valcke, \& Van Braak, 2008). Furthermore, ICT is still not part of everyday 
teaching routines in most schools (Vrasidas, 2015) despite the recognition on many levels (teachers, school leaders, politics) of its importance for learning in the 21st century. In addition, these outcomes are cause for worry for education as well as science. Researchers who want to investigate the effects of the use of DLMs in relation to learning outcomes of students or other related topics only investigate a specific group of teachers. After all, almost all teachers must integrate ICT in their daily teaching practises before valid results can be reported.

The research question addressed was whether perceptions of successful use of DLMs would strengthen (or weaken) teachers' behavioural intentions to use DLMs again during classes on a regular basis, that is, several times a week in the coming school year. Indeed, previous research has shown that perceived success of past behaviour is an important predictor of performing the same behaviour in the future provided that all conditions have remained the same (Ouellette \& Wood, 1998). In our study we specifically focused on the effect of perceived success of using DLMs regularly during classes in the past school year and whether this perceived success would correspond with the strength of teachers' behavioural intention to regularly use DLMs during classes in the coming school year. In addition, we also wanted to see whether teachers who reported to have had no plans at all to use DLMs during classes now have developed the intention to do so on a regular basis.

In this article, we first elaborate on the Reasoned Action Approach (RAA) of Fishbein and Ajzen (2010) as this was the framework we used throughout our study. We proceed by discussing two analytical methods that were applied in our study, and finally, the results, discussion, and conclusion are presented.

\section{Theoretical Framework}

For answering the research question, whether perceived success is affecting teachers' behavioural intention to use DLMs regularly in the coming year, the Reasoned Action Approach (RAA) of Fishbein and Ajzen (2010) was used. The central variable in RAA is the behavioural intention that reflects the willingness (or reluctance) to show a particular desired behaviour. In our study, the behavioural intention is the regular use (i.e., several times a week) of DLMs by teachers in their lessons in the coming year. Fishbein and Ajzen (2010) indicated that the behavioural intention is a predictor of the actual behaviour; however, the relationship between behavioural intention and actual behaviour is not perfect. Two groups of factors moderate this relationship between behavioural intention and actual behaviour. The first group is formed by individual factors (e.g., the knowledge and skills turned out to be insufficient to perform the behaviour) and the second group is formed by the environmental factors that may prevent the behaviour to be performed (e.g., a broken computer or bad internet connection). The two groups of factors are summarized as actual behavioural control in RAA. Actual behavioural control is the counterpart of perceived behavioural control, which is a direct determinant of behavioural intention. Perceived behavioural control (or self-efficacy, see Bandura, 1986), is the belief that the behaviour can be performed because one trusts in her or his own capacity to do so. This conviction is based in one's belief of possessing the necessary knowledge and skills and the belief that one can exert sufficient control to cope with unexpected problems. Fishbein and Ajzen (2010) designated these beliefs as the capacity and autonomy dimension, respectively, of perceived behavioural control. As the gap is narrowing between perceived behavioural control and actual behavioural control, the relationship between behavioural intention and actual behaviour becomes stronger. 
Next to perceived behavioural control, attitude and perceived norm are the other two direct determinants of behavioural intention. Attitude is the extent to which one takes a favourable or unfavourable position in relation to the desired behaviour. In other words, teachers may have formed a more or less favourable position over the regular use of DLMs in the classroom. Perceived norm is to be regarded as the pressure exerted by the social environment to exhibit certain behaviour. This social pressure is the result of the belief that significant others may have certain opinions on whether or not to perform a particular behaviour. As the perceived norm becomes stronger, whilst attitude and perceived behavioural control remain constant, the more likely it will be that the behavioural intention also gets stronger. In other words, when a school leader sets the norm of regular using of DLMs in class, this will contribute quite strongly to the perceived social pressure and thus to the behavioural intention to actually do this. Figure 1 shows the RAA model. In this figure, the grey areas indicate the variables involved in this study. Although not indicated in the figure, with "use of DLMs" is meant the "regular use of DLMs," that is, several times a week in the coming school year.

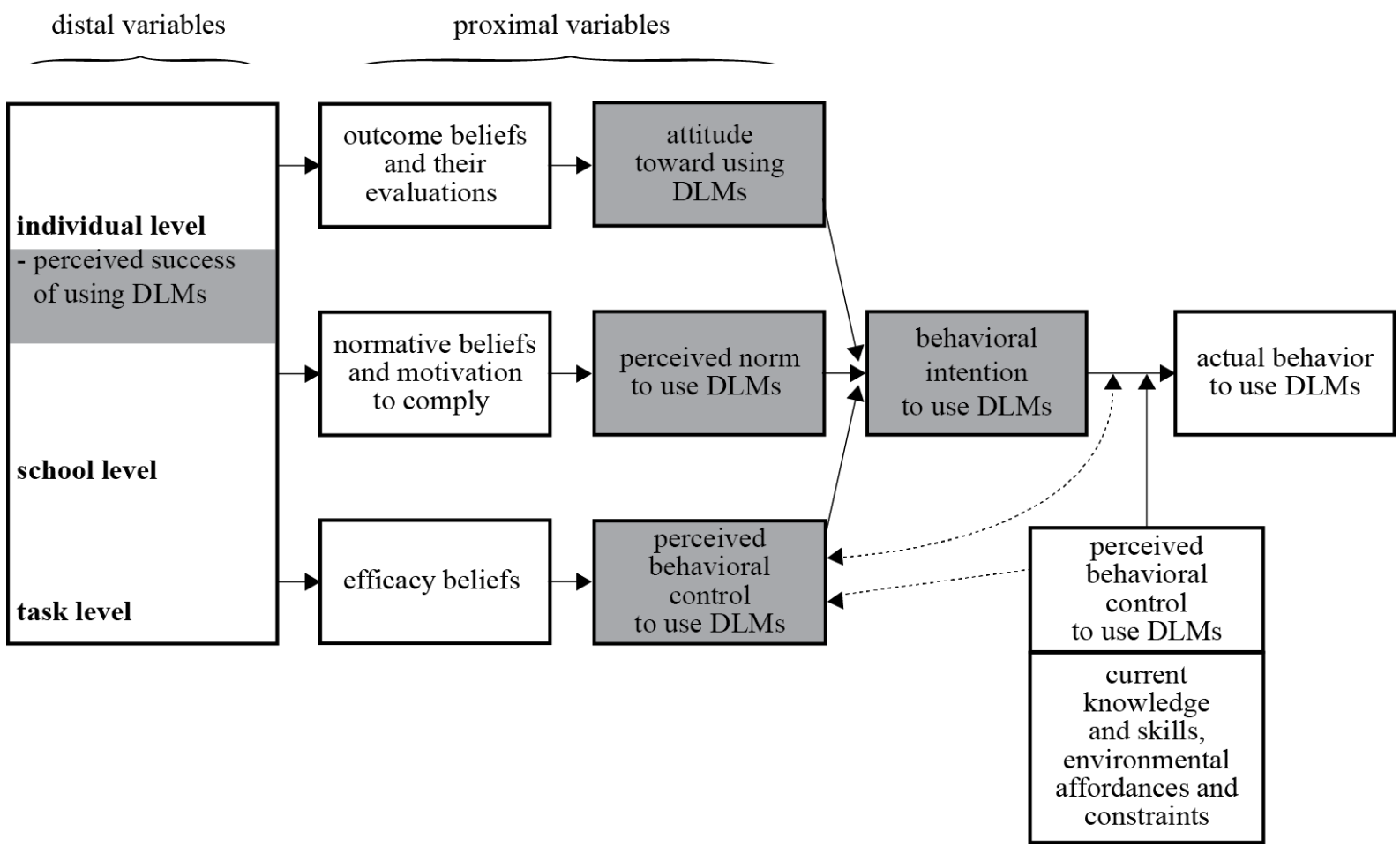

Figure 1. The Reasoned Action Approach applied to teachers' use of DLMs.

Figure 1 also shows that attitude, perceived norm, and perceived behavioural control are in turn formed by successively outcome expectations and their evaluations, normative beliefs, and motivation to comply, and control beliefs regarding the performance of the behaviour. As the current study does not consider these beliefs, we do not describe them here. All the variables so far are usually designated as proximal variables, as they are the closest variables that can influence the behavioural intention to perform or not to perform a certain behaviour (see Figure 1). In contrast to the proximal variables, distal variables are variables that influence the behavioural intention in an indirect way, that is, via the proximal variables. Distal variables exercise their influence at the individual level, the school level, or at the task level. In our study, the only distal variable we considered was perceived success of actual using DLMs regularly in the past school year, which is a variable at the individual level. Perceived 
success is measured in the eyes of the teacher, in other words: teachers' overall assessment of their own success in using actual DLMs. Perceived success may vary from teacher to teacher. Generally, perceived success of previously performed behaviour affects the three proximal variables in the following ways:

- Attitude: outcome expectations proved to be true or false and their evaluations may be positively or negatively changed through the experience. For instance, teachers may have experienced that using DLMs in the lessons made these classes more interesting and the students more enthusiastic. At the same time, the teacher may have also experienced that the extra time invested in lesson preparation was not as high as expected.

- Perceived norm: experiences may strengthen or weaken motivation to comply with the normative beliefs of significant others. For instance, teachers may become more motivated to comply with the opinion of the school director that teachers should use DLMs regularly for a number of reasons, possibly for the same reasons that may have changed the teachers' attitude. If teachers experienced that using DLMs made classes more interesting and that the extra preparation time was acceptable, teachers may find it less of a problem to satisfy the school director's opinion as the use of DLMs regularly may become something they would do anyway.

- Perceived behavioural control: the behaviour could be demonstrated to be carried out, or not, in problematic circumstances. The teacher noted that problems occurred less frequently than was initially thought and that the problems were dissolved more easily then expected (c.f., Hagger, Chatzisarantis, \& Biddle, 2001).

Therefore, in this study we expected that the effect of perceived success in using DLMs on behavioural intention is mediated by attitude, perceived norm, and perceived behavioural control.

\section{Research Question and Hypotheses}

The main research question was formulated as follows:

Do perceptions of success in using of DLMs regularly (i.e., several times a week) during classes in the past year strengthen (or weaken) teachers' behavioural intentions to use DLMs again on the same regular basis in the coming year?

From this research question the following hypotheses were derived:

H1a Teachers who were "successful to very successful" in using DLMs regularly during classes in the past year will have a "strong intention" to use DLMs again on a regular basis.

H1b Teachers who had "no to moderate success" in using DLMs regularly during classes in the past year will have a "no to a weak intention" or a "moderate intention" to use DLMs again on a regular basis.

H1c Teachers who had "no intention at all" to use DLMs regularly during classes in the past year will have a "no to a weak intention" to use DLMs on a regular basis. 
H2a The influence of perceived success on the behavioural intention to use DLMs regularly during classes in the coming year is mediated by the attitude to do so.

H2b The influence of perceived success on the behavioural intention to use DLMs regularly during classes in the coming year is mediated by the perceived norm to do so.

H2c The influence of perceived success on the behavioural intention to use DLMs regularly during classes in the coming year is mediated by the perceived behavioural control to do so.

To test these hypotheses, the variable self-prediction to actually exhibit the desired behaviour was used in the study. Self-prediction was used as a discriminatory factor in the population to distinguish the group of teachers that predict that they are going to use DLMs on a regular basis from the group of teachers that predict that they are not going to use DLMs on a regular basis. It is important that selfprediction should not be confused with behavioural intention. Armitage and Conner (2001) indicated that there is a conceptual difference between behavioural intentions and self-prediction: there is a difference between what a person's intention is to do and what someone actually thinks she or he is going to do. They argued this reasoning as follows:

(S)elf-predictions should provide better predictions of behaviour as they are likely to include a consideration of those factors which may facilitate or inhibit performance of a behaviour, as well as a consideration of the likely choice of other competing behaviours. Sheppard et al.'s meta-analysis supported this view: measures of self-predictions were found to have stronger relationships with behaviour (mean $\mathrm{r}=.57$ ) than did behavioural intentions (mean $\mathrm{r}=.49$ ), although attitude and subjective norm accounted for more of the variance in intentions (mean $\mathrm{R}=.73$ ) than self-predictions (mean $\mathrm{R}=.61$ ) (p. 477).

Self-prediction is usually measured by items such as "how likely is it that you are going to perform [behaviour $\mathrm{x}$ ]?" and behavioural intentions by items such as "do you plan to perform [behaviour $\mathrm{x}$ ]?”.

\section{Method}

\section{Participants}

A large number of teachers from all levels of the Dutch education $(\mathrm{N}=1587)$ have completed an online questionnaire administered by TNS / NIPO in the Spring of 2012. Table 1 displays the distribution of teachers to the variables school sector, gender, and age.

Table 1

Teachers Distributed Over School Sector, Gender, and Age (N=1587)

\begin{tabular}{lccc}
\hline \multirow{2}{*}{ School sector } & \multicolumn{2}{c}{ Gender } & \multirow{2}{*}{ Age M (SD) } \\
\cline { 2 - 3 } & man & woman & $41,9(12.4)$ \\
Primary & $120(16.3 \%)$ & $614(83.7 \%)$ & $45,8(12.1)$ \\
VET (lower) & $142(60.7 \%)$ & $92(39.3 \%)$ & $42,8(12.6)$ \\
Secondary & $134(50.6 \%)$ & $131(49.4 \%)$ & $46,9(12.2)$ \\
VET (middle) & $86(54.4 \%)$ & $72(46.9 \%)$ & $41,1(14.1)$ \\
Higher education & $105(53.6 \%)$ & $91(46.4 \%)$ & $43.3(12.6)$ \\
Total & $587(37.0 \%)$ & $1000(63.0 \%)$ & \\
\hline
\end{tabular}




\section{Measuring Instruments}

The questionnaire consisted of a number of measuring instruments in order to investigate the various aspects related to teachers' intended use of DLMs. As no standard validated measurement instrument for each of the variables was available, the researchers constructed measurement instruments for all the variables according to the instructions and guidelines of Fishbein and Ajzen (2010).

Self-prediction for the regular use of DLMs during classes was measured with one item: "Do you think that you will use digital learning materials in your lessons / lectures on a regular basis in the coming year?" Only a yes or no answer could be given on this question.

Perceived success was also measured with one item: "To what extent were you actually successful in your intentions to use digital learning materials in your lessons / lectures on a regular basis in the past year?" A 7-point Likert scale was used with answer categories: $1=$ "completely unsuccessful" to 7 = "completely successful." If teachers did not intend to use DLMs in the past year, they had the option to answer "I had no intention to use digital learning materials."

The behavioural intention was measured using four items (e.g., "I intend to regularly use digital learning materials during classes in the coming year"). All items of behavioural intention used a 7-point Likert scale with answer categories: $1=$ "absolutely disagree" to $7=$ "strongly agree." The four items were in line with the standard items that are commonly used to measure behavioural intention and they were also recommended by Fishbein and Ajzen (2010, also see Ajzen, 1991).

Attitude was not directly measured in this study. Instead, a proxy for attitude was used. Teachers who predicted to regularly use DLMs during classes in the coming year could indicate from a structured list of 22 items regarding the potential benefits of DLMs usage which item was applicable to them. These benefits addressed things like, DLMs provide clearer lessons, give more insight, and work better. Similarly, teachers who predict not to regularly use DLMs during classes in the coming year could indicate which item was applicable to them from a structured list of 21 items regarding the potential disadvantages of DLMs usage. These disadvantages included, no added value, not necessary, and not useful. The number of advantages and the number of disadvantages that teachers consider to be applicable to them were used to calculate a rating for attitude.

Perceived norm is measured by one item: "All things considered, to what extent do you experience social pressure of your school leader, team leaders, colleagues, parents, and so on to regularly use digital learning materials during classes in the coming year?" A 7-point Likert scale was used. The response categories were: 1 = "absolutely no pressure" to 7 = "extraordinary pressure."

Finally, perceived behavioural control was measured with 13 items on two dimensions: capacity and autonomy (see Fishbein \& Ajzen, 2010). The capacity dimension comprised six items (e.g., "I think I will manage to use digital learning materials on a regular basis"). The autonomy dimension consisted of seven items (e.g., "In most cases it is up to me to determine whether I am going to use digital learning materials or not and whether I am going to do this on a regular basis"). All perceived behaviour control items used a 7-point Likert scale with answer categories: $1=$ "absolutely disagree" to $7=$ "strongly agree." 


\section{Analysis}

Table 2 list for each variable the mean (M) and standard deviation $(S D)$ as well as the correlations between these variables.

Table 2

Descriptive Data of the Used Variables $(N=1587)$.

\begin{tabular}{|c|c|c|c|c|c|c|c|c|c|}
\hline & \multirow[b]{2}{*}{ Variable } & \multirow[b]{2}{*}{$\begin{array}{l}\text { Number } \\
\text { of items }\end{array}$} & \multirow[b]{2}{*}{$M$} & \multirow[b]{2}{*}{$S D$} & \multirow[b]{2}{*}{ Range } & \multicolumn{4}{|c|}{ Pearson's r } \\
\hline & & & & & & $\mathbf{1}$ & $\begin{array}{l}\mathbf{2 a} \\
\mathbf{2 b}\end{array}$ & 3 & 4 \\
\hline 1 & Behavioural intention & 4 & 5.03 & 1.30 & $1-7$ & $.94^{\dagger}$ & & & \\
\hline $2 a$ & Attitude (self-prediction = 'yes') & 1 & 1.29 & 1.13 & $0-6$ & $.45^{* *}$ & & & \\
\hline $2 b$ & Attitude (self-prediction = 'no') & 1 & 0.29 & 0.60 & $0-4$ & $-.47^{* * *}$ & & & \\
\hline 3 & Perceived norm & 1 & 2.54 & 1.50 & $1-7$ & $.05^{*}$ & $\begin{array}{l}.04 \\
-.09 *\end{array}$ & & \\
\hline 4 & Perceived behavioural control & 14 & 65.00 & 10.93 & $22-91$ & $.63^{* * *}$ & $\begin{array}{l}.33^{* *} \\
-.29^{* * *}\end{array}$ & $-.11^{* *}$ & $.89^{\dagger}$ \\
\hline 5 & Previous success & 1 & 4.62 & 2.00 & $0-7$ & $.59^{* *}$ & $\begin{array}{l}.39^{* *} \\
-.39^{* *}\end{array}$ & -.01 & $.57^{* * *}$ \\
\hline
\end{tabular}

** $p<.01 * p<.05$ (two sided)

+Cronbachs' alpha

Note 1: Depending on self-prediction, teachers' attitude will have positive or negative wording. Therefore, the analyses were carried out separately for self-prediction = "yes" and self-prediction = "no."

To test the hypotheses, two analytical methods were applied. The first analytical method used cross tabs / multinomial logistic regression for analyzing teachers flows. That is, the relationship between teachers 1) who had perceived some degree of success of actual using DLMs regularly during classes in the past year or 2) who had no intention at all in the past year to use DLMs, and how they flow into three ordered categories of different strengths of the behavioural intention to use DLMs regularly in the coming year. To this end, we constructed a category of teachers who were "not to moderate successful" of actual using DLMs and another category of those who were "successful to very successful" of this. Teachers who had no intention at all of using DLMs formed a third category. The three ordered categories of different strengths of the behavioural intention were respectively "no to weak intention," "moderate intention," and "strong intention." All categories were constructed by recoding the original data.

The second analytical method used the process method of Hayes (2013) and SEM techniques to analyse the influence of perceived success in the past year on the behavioural intention to use DLMs regularly again in the coming year. It was investigated whether perceived success indirectly effected (through the proximal variables attitude, perceived norm, and perceived behavioural control) and / or directly affected behavioural intention. Past research suggests that there could be a direct effect (i.e., the previous use of DLMs had a direct effect on behavioural intention, see Kreijns, Van Acker, Vermeulen, \& van Buuren, 2013). It is noted that the teachers who have had no intention at all to use DLMs in the past school year could not be included in this analysis.

This latter implied that for both of the two analytical methods, a distinction has to be made in the population of teachers who predicted that they will use DLMs regularly during classes: (self-prediction = "yes"; $n_{\text {yes }}=1221$ for the first analytical method and $n_{\text {yes }}=1173$ for the second method); and the population of teachers who predicted that they will not use DLMs (self-prediction = "no"; $\mathrm{n}_{\mathrm{no}}=336$ for the first analytical method and $\mathrm{n}_{\mathrm{no}}=\mathbf{2 6 2}$ for the second method). 


\section{First Analytical Method}

As pointed out above, we have constructed three categories of teachers based on their previous success in the past year and on the fact that they had no intention at all to use DLMs:

1. The category "had no intention" consisted of teachers who had indicated having no intention at all to use DLMs in the past year $\left(\mathrm{N}_{\mathrm{s}}(1)=152\right)$.

2. The category "not to moderate success" consisted of teachers who had scored a 1 (= completely failed) to 5 (= somewhat successful $)\left(\mathrm{N}_{\mathrm{s}}(2)=783\right)$.

3. The category "successful to very successful" included teachers who had scored a 6 (= successful) or a 7 ( $=$ completely successful $)\left(\mathrm{N}_{\mathrm{s}}(3)=652\right)$.

We also constructed three categories for the behavioural intention to use DLMs regularly in the coming year:

1. The category "no to weak intentions" included the scores between 1 and $4.3(\approx 1 / 3$ of the volume). The number of teachers who fell into this category was referred to as $\mathrm{N}_{\mathrm{i}}(1)$.

2. The category "moderate intentions" included the scores between 4.4 and $5.75(\approx 1 / 3$ of the volume). The number of teachers who fell into this category was referred to as $\mathrm{N}_{\mathrm{i}}(2)$

3. The category "strong intentions" included the scores between 5.8 and $7(\approx 1 / 3$ of the volume). The number of teachers who fell into this category was referred to as $\mathrm{N}_{\mathrm{i}}(3)$.

Depending on the Unit of Analysis (UoA) and the analysis techniques used, different teacher flows could be determined. For the analyses, both the individual teacher and the teacher group as UoA was used. When the individual teacher was the UoA, multinomial logistic regression was used; and when the teacher group was the UoA, crosstabs was used. The resulting teacher flows are reported in Table 3 . From this figure, and for the case of a positive self-prediction (i.e., teachers predict that they are going to use DLMs on a regular basis), we clearly see that the teachers' flows using crosstabs were above expectations except for the group teachers who were successful or very successful. The group teachers who initially had no intention to use DLMs showed a moderate intention to use DLMs regularly in the coming year, whilst it was expected that this group would have a no to weak intention. The group of teachers who had no or moderate success, showed a strong behavioural intention to use DLMs regularly in the coming year, whilst it was expected that this group would have a no to weak intention or a moderate intention. For the case of a negative self-prediction (i.e., teachers predict that they are not going to use DLMs on a regular basis in the coming year), all teacher flows were according to our expectation.

For the individual teacher as the UoA, multinomial logistic regression in SPSS version 20 was performed to study the influence of perceived success (i.e., "had no intention," "not to moderate success," and "successful to very successful" in the past year) and whether or not the teacher predicted to use DLMs regularly during classes in the coming year (i.e., "yes" or "no") on teachers' behavioural intention to have a "no to weak," "moderate," or "strong" behavioural intention. Self-prediction to use DLMs regularly in the coming year was a covariate categorical variable. The full model was statistically significant: $\chi^{2}(6,1587)=752.50, p<.001$. In other words, the model was capable to significantly distinguish teachers who expressed having a "no to weak," "moderate," or "strong" behavioural 
intention from each other on the basis of perceived success and self-prediction with a statistically explained variance of about .40 (Cox \& Snell Pseudo R-Square $=.38$ and Nagelkerke Pseudo R-Square $=.43)$.

Table 3

Overview of Teachers Flows

\begin{tabular}{|c|c|c|c|c|c|c|}
\hline \multirow[b]{2}{*}{$\begin{array}{l}U o A \\
\text { (analysis) }\end{array}$} & \multicolumn{2}{|c|}{ No to weak intention } & \multicolumn{2}{|c|}{ Moderate intention } & \multicolumn{2}{|c|}{ Strong intention } \\
\hline & $\begin{array}{c}\text { Group } \\
\text { (crosstabs) }\end{array}$ & $\begin{array}{c}\text { Individual } \\
\text { (multinomial } \\
\text { logistic regression) }\end{array}$ & $\begin{array}{c}\text { Group } \\
\text { (crosstabs) }\end{array}$ & $\begin{array}{c}\text { Individual } \\
\text { (multinomial } \\
\text { logistic regression) }\end{array}$ & $\begin{array}{c}\text { Group } \\
\text { (crosstabs) }\end{array}$ & $\begin{array}{c}\text { Individual } \\
\text { (multinomial } \\
\text { logistic regression) }\end{array}$ \\
\hline \multicolumn{7}{|l|}{ Self-prediction = 'yes' } \\
\hline 'Had no intentions' & o & 26 & 48 & 14 & $\mathrm{O}$ & 8 \\
\hline $\begin{array}{l}\text { 'Not to moderate } \\
\text { success' }\end{array}$ & o & 156 & $\mathrm{O}$ & 293 & 559 & 110 \\
\hline $\begin{array}{l}\text { 'Successful to very } \\
\text { successful' }\end{array}$ & o & 40 & o & 188 & 614 & 386 \\
\hline \multicolumn{7}{|l|}{ Self-prediction = 'no' } \\
\hline 'Had no intentions' & 104 & 98 & o & 6 & o & o \\
\hline $\begin{array}{l}\text { 'Not to moderate } \\
\text { success' }\end{array}$ & o & 149 & 224 & 66 & $\mathrm{O}$ & 9 \\
\hline $\begin{array}{l}\text { 'Successful to very } \\
\text { successful' }\end{array}$ & o & 13 & o & 16 & 38 & 9 \\
\hline
\end{tabular}

To gain more insight, Figure $2 \mathrm{a}$ and Figure $2 \mathrm{~b}$ were constructed to visualize the teachers flows (UoA is the individual teacher).

previous success

To what extent were you actually successful in your intentions to use digital learning materials in your lessons/lectures on a regular basis in the past year? self-prediction

Do you think that you will use digital learning materials in your lessons/lectures on a regular basis for the coming year? Self-prediction $=$ yes

$$
\mathrm{N}=1587 \text {; }
$$

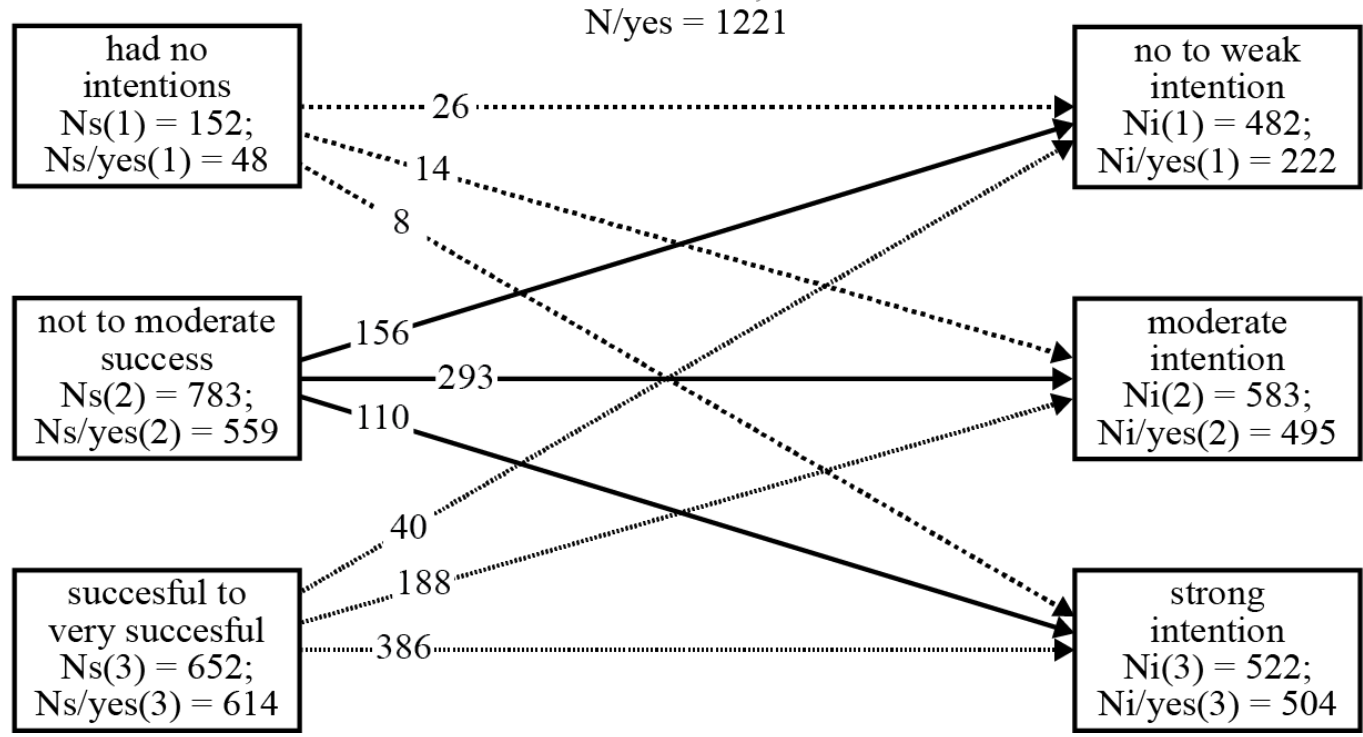

Figure 2a. Teachers flows for the population of teachers who predicted that they will use DLMs regularly during classes. 
previous success

To what extent were you actually successful in your intentions to use digital learning materials in your lessons/lectures on a regular basis in the past year? self-prediction

Do you think that you will use digital learning materials in your lessons/lectures on a regular basis for the coming year? Self-prediction $=$ no behavioral intention

Intention to use digital learning materials in your lessons/lectures on a regular basis for the coming year

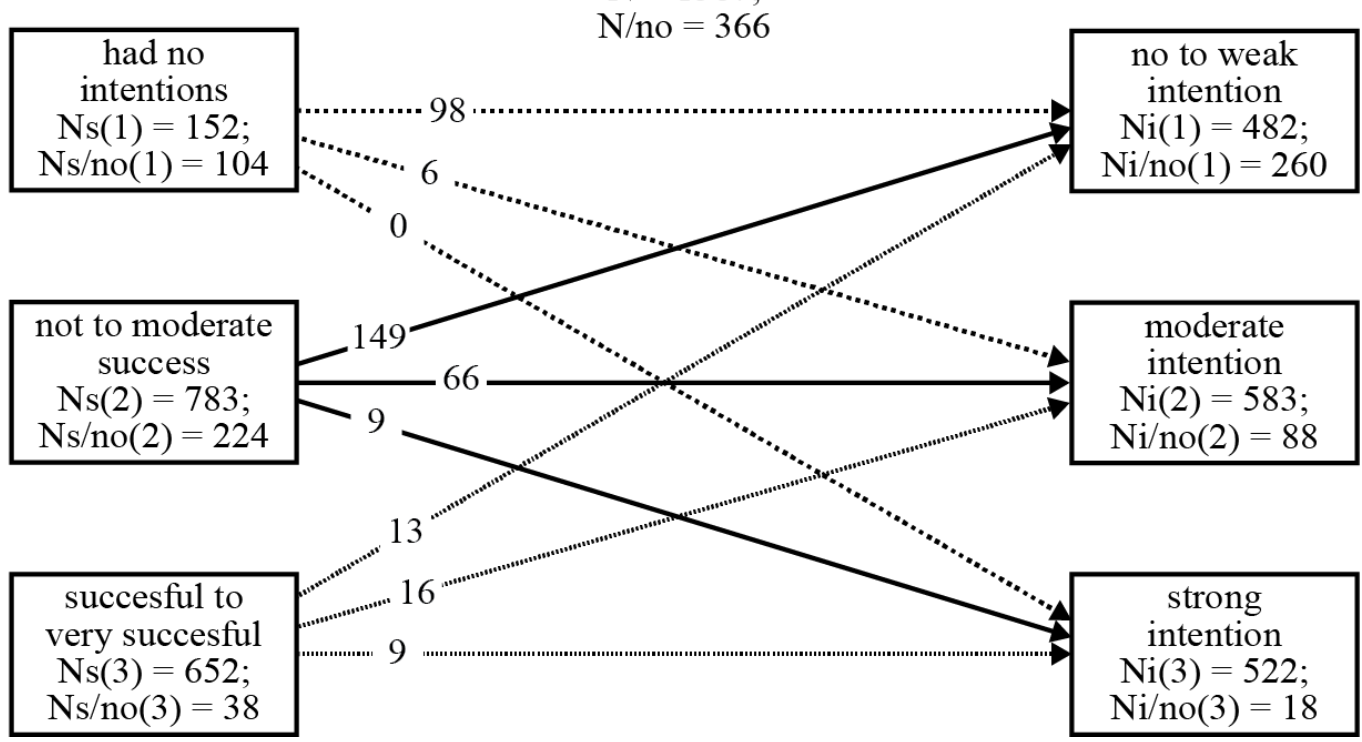

Figure $2 b$. Teachers flows for the population of teachers who predicted that they will not use DLMs regularly during classes.

From the teacher population who predicted that they will use DLMs regularly during classes in the coming year, the majority of teachers in each category proved-as was expected-to flow into the corresponding categories (i.e., "had no intention" flowed into "no to weak intention," "no to moderate success" flowed into "moderate intention," and "successful to very successful" flowed into "strong intention"). However, other flows were-as was not expected-also be possible. For example, it was surprising that from this population of teachers, some of the teachers who fell in the category "successful to very successful" flowed into the category "moderate intention" (188 of the 614 teachers) and into the category "no to weak intention" (40 of the 614 teachers). Likewise, it was surprising that teachers who fell in the category "'ad no intention" and, thus, had no experience of success in using DLMs whatsoever nevertheless decided to express a "strong intention" ( 8 of the 48 teachers) to use DLMs regularly in the coming year.

In line with our expectations, from the teacher population who predicted that they will not use DLMs regularly during classes in the coming year, the majority of teachers in each category developed a corresponding "no to weak intention" or a "moderate intention" to use DLMs regularly in the coming year. But here too there were unexpected flows. Teachers who were "successful to very successful" surprisingly flowed into the category "no to weak intention" (13 of the 38 teachers).

The reasons for all of these unexpected flows were further explored in the next analyses (see the next section).

\section{Second Analytical Method}


To determine the direct and indirect (via the proximal variables attitude, perceived norm, and perceived behavioural control) effects of success on the behavioural intention, we followed the Hayes process method (2013, also see Preacher \& Hayes, 2008) and used the associated PROCESS macro package SPSS (Hayes, 2012). In this analysis, the original categories for previous success and behavioural intention, and not the three constructed categories from the first analytical method, were used. Consequently, the population of teachers who "had no intention" to use DLMs regularly in the past year $\left(\mathrm{N}_{\mathrm{s}}(1)=152\right)$ were not included in the analysis. This exclusion affected the composition of the sample. For the sake of completeness, the following tables (Table 4 and Table 5) give the background data of the remaining $\mathrm{N}=1587-152=1435$ displayed. Comparison of the two tables with the backgrounds of the teachers shows hardly any differences in values and standard deviations. However, the average age is slightly higher in the smaller sample.

Table 4

Teachers Distributed Over School Sector, Gender, and Age (N=1435)

\begin{tabular}{lrcc}
\hline \multirow{2}{*}{ School sector } & \multicolumn{2}{c}{ Gender } & \multirow{2}{*}{ Age M (SD) } \\
\cline { 2 - 3 } Primary & $115(17.0 \%)$ & $560(83.0 \%)$ & $44,9(12.5)$ \\
VET (lower) & $137(63.1 \%)$ & $80(36.9 \%)$ & $46.4(12.0)$ \\
Secondary & $122(51.0 \%)$ & $117(49.0 \%)$ & $42,8(12.6)$ \\
VET (middle) & $77(54.6 \%)$ & $64(45.4 \%)$ & $47.0(12.0)$ \\
Higher education & $88(54.0 \%)$ & $75(46.0 \%)$ & $44.5(14.0)$ \\
Total & $539(37.6 \%)$ & $896(62.4 \%)$ & $43.5(12.6)$ \\
\hline
\end{tabular}

As can be seen in Table 5 the values for the mean $(M)$, standard deviation $(S D)$ of the variables, the correlation between the variables, and Cronbach's alpha values for internal consistency proved to be of minimal difference between the samples (compare Table 2 with Table 5).

Table 5

Descriptive Data of the Used Variables $(N=1435)$.

\begin{tabular}{|c|c|c|c|c|c|c|c|c|c|}
\hline & \multirow[b]{2}{*}{ Variable } & \multirow[b]{2}{*}{$\begin{array}{l}\text { Number } \\
\text { of items }\end{array}$} & \multirow[b]{2}{*}{$M$} & \multirow[b]{2}{*}{$S D$} & \multirow[b]{2}{*}{ Range } & \multicolumn{4}{|c|}{ Pearson's r } \\
\hline & & & & & & $\mathbf{1}$ & $\begin{array}{l}\mathbf{2 a} \\
\mathbf{2 b} \\
\end{array}$ & 3 & 4 \\
\hline 1 & Behavioural intention & 4 & 5.20 & 1.16 & $1-7$ & $.93^{+}$ & & & \\
\hline $2 \mathrm{a}$ & Attitude (self-prediction = 'yes') & 1 & 1.39 & 1.12 & $0-6$ & $.40^{* *}$ & & & \\
\hline $2 b$ & Attitude (self-prediction = 'no') & 1 & 0.23 & 0.54 & $0-4$ & $-.40^{* * *}$ & & & \\
\hline 3 & Perceived norm & 1 & 2.60 & 1.50 & $1-7$ & $-.01 *$ & $\begin{array}{l}.01 \\
-.05\end{array}$ & & \\
\hline 4 & Perceived behavioural control & 14 & 65.75 & 10.68 & $22-91$ & $.63^{* * *}$ & $\begin{array}{l}.29^{* *} \\
-.24^{* * *}\end{array}$ & $-.15^{* *}$ & $.89^{+}$ \\
\hline 5 & Previous success & 1 & 5.11 & 1.39 & $1-7$ & $.59^{* *}$ & $\begin{array}{l}.36^{* *} \\
-.37^{* * *}\end{array}$ & -.04 & $.58^{* *}$ \\
\hline
\end{tabular}

The Hayes (2013) process method for mediation tests the following four relationships:

1. Whether there is a significant direct relationship between the mediator (i.e., attitude, perceived norm, or perceived behavioural control) and the dependent variable (i.e., behavioural intention). 
2. Whether there is a significant direct relationship between the independent variable (i.e., previous success) and the mediator.

3. Whether there is a significant indirect effect of the independent variable on the dependent variable via the mediator.

4. Whether the direct effect of the independent variable on the dependent variable remains significant after controlling for the mediation effect (in other words, whether there is full or partial mediation and, thus, whether a direct effect is present next to the indirect effect).

The analysis was performed twice: for the population of teachers who predicted that they will use DLMs regularly during classes in the coming year and for the population of teachers who predicted to not do so.

\section{distal variables \\ self-prediction}

\section{proximal variables}

Do you think that you will use digital learning materials in your lessons/lectures on a regular basis in the coming year? Self-prediction $=$ yes

$$
\begin{gathered}
\mathrm{N}=1435 ; \\
\text { N/yes }=1173
\end{gathered}
$$

perceived success of using DLMs

\section{?} (1)

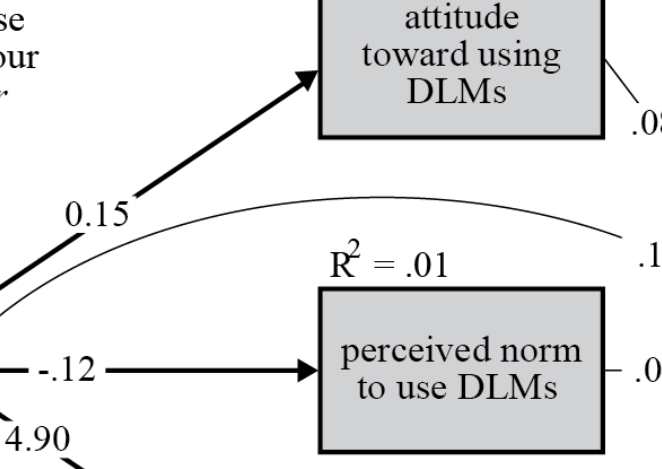

attitude toward using

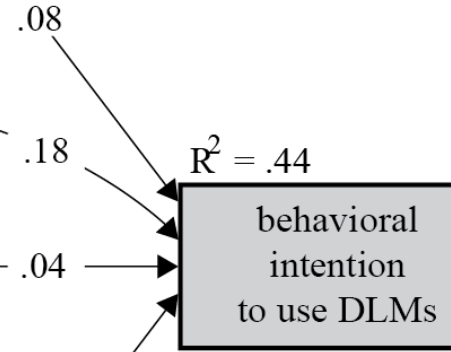

Figure $3 a$. Results of the mediation analysis of the model for the case that self-prediction = "yes." The displayed (unstandardized) path coefficients are significant at $p<.001$ level. Non-significant paths are shown grey in the figure. Thick black lines reflect the indirect effect of the distal variable via the three mediators. 
distal variables

self-prediction

\section{proximal variables}

$\mathrm{R}^{2}=.00$

attitude

toward using

DLMs

digital learning materials in your

lessons/lectures on a regular

basis for the coming year?

Self-prediction $=$ no

$\mathrm{N}=1435$

$\mathrm{N} / \mathrm{no}=262$
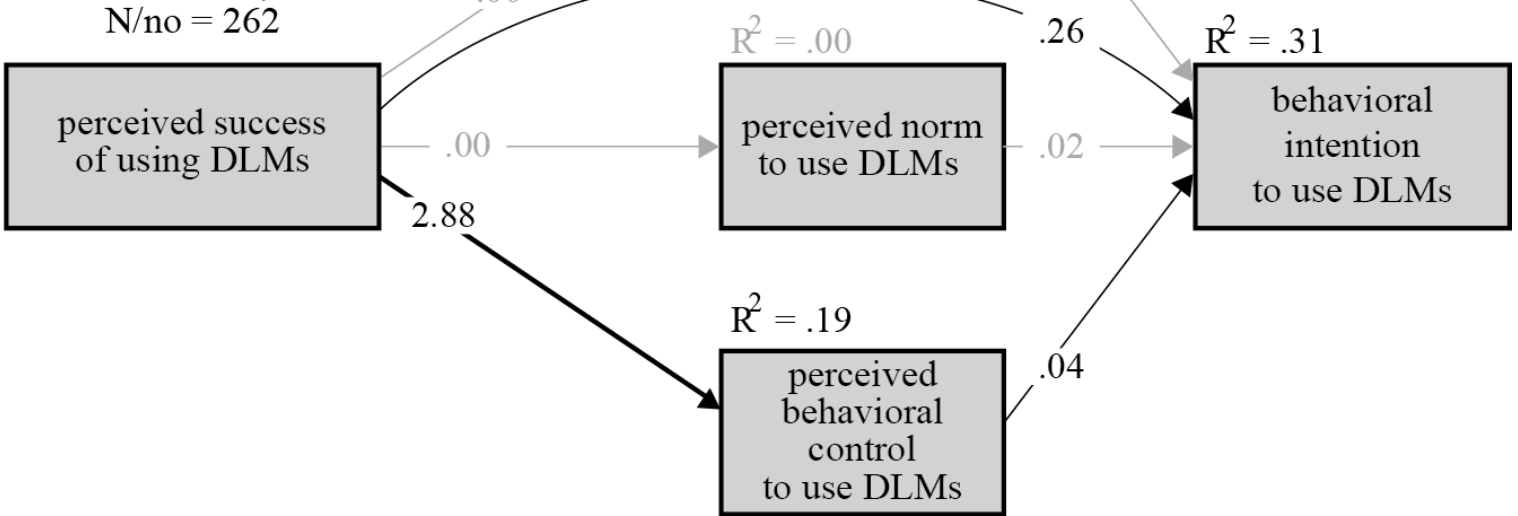

Figure $3 b$. Results of the mediation analysis of the model for the case that self-prediction = "no"). The displayed (unstandardized) path coefficients are significant at $p<.001$ level. Non-significant paths are shown grey in the figure. Thick black lines reflect the indirect effect of the distal variable via the three mediators.

Table 6

Tests for Determining the Significance of the Indirect Effects of the Independent Variable Success. B Indicates the Strength of the (Unstandardized) Indirect Effect

\begin{tabular}{|c|c|c|c|c|}
\hline \multirow[b]{2}{*}{ Distal variables } & \multirow[b]{2}{*}{ Mediator } & \multirow[b]{2}{*}{$\mathrm{B}$} & \multicolumn{2}{|c|}{ Confidence interval } \\
\hline & & & Lower limit & Upper limit \\
\hline \multicolumn{5}{|c|}{ Self-prediction = 'yes' } \\
\hline \multicolumn{5}{|c|}{ Success in the past year } \\
\hline & total & $.24 *$ & .21 & .28 \\
\hline & attitude & $.01 *$ & .01 & .02 \\
\hline & perceived norm & -.00 & -.01 & -.00 \\
\hline & perceived behaviour control & $.24 *$ & .20 & .27 \\
\hline \multicolumn{5}{|c|}{ Self-prediction = 'no' } \\
\hline \multicolumn{5}{|c|}{ Success in the past year } \\
\hline & total & $.12 *$ & .07 & .17 \\
\hline & attitude & .00 & -.00 & .01 \\
\hline & perceived norm & .00 & -.01 & .01 \\
\hline & perceived behaviour control & $.11 *$ & .07 & .17 \\
\hline
\end{tabular}

*Note. Significant unstandardized path coefficient B.

To determine the fit of the two models in Figure $3 \mathrm{a}$ and Figure $3 \mathrm{~b}$, Structural Equation Modelling (SEM) was used with AMOS 5. Fit indices showed a reasonable fit of the models: for the population of teachers who predicted that they will use DLMs regularly was the CFI $=.971$ and RMSEA $=.10$ (CI: $07-.13$ ) and for the population of teachers who predicted that they will not use DLMs regularly was the CFI = .972 and RMSEA $=.04$ (CI: $0-.11)$. 
An overview of the unstandardized path coefficients resulting from the Hayes (2013) analysis and the SEM analysis are shown in Table 7 for comparison of the values of both mediation analyses. The difference between the values from both analyses do not differ greatly.

Table 7

Comparison of the Values of the Unstandardized Path Coefficients from the Hayes Analysis and the SEM Analysis

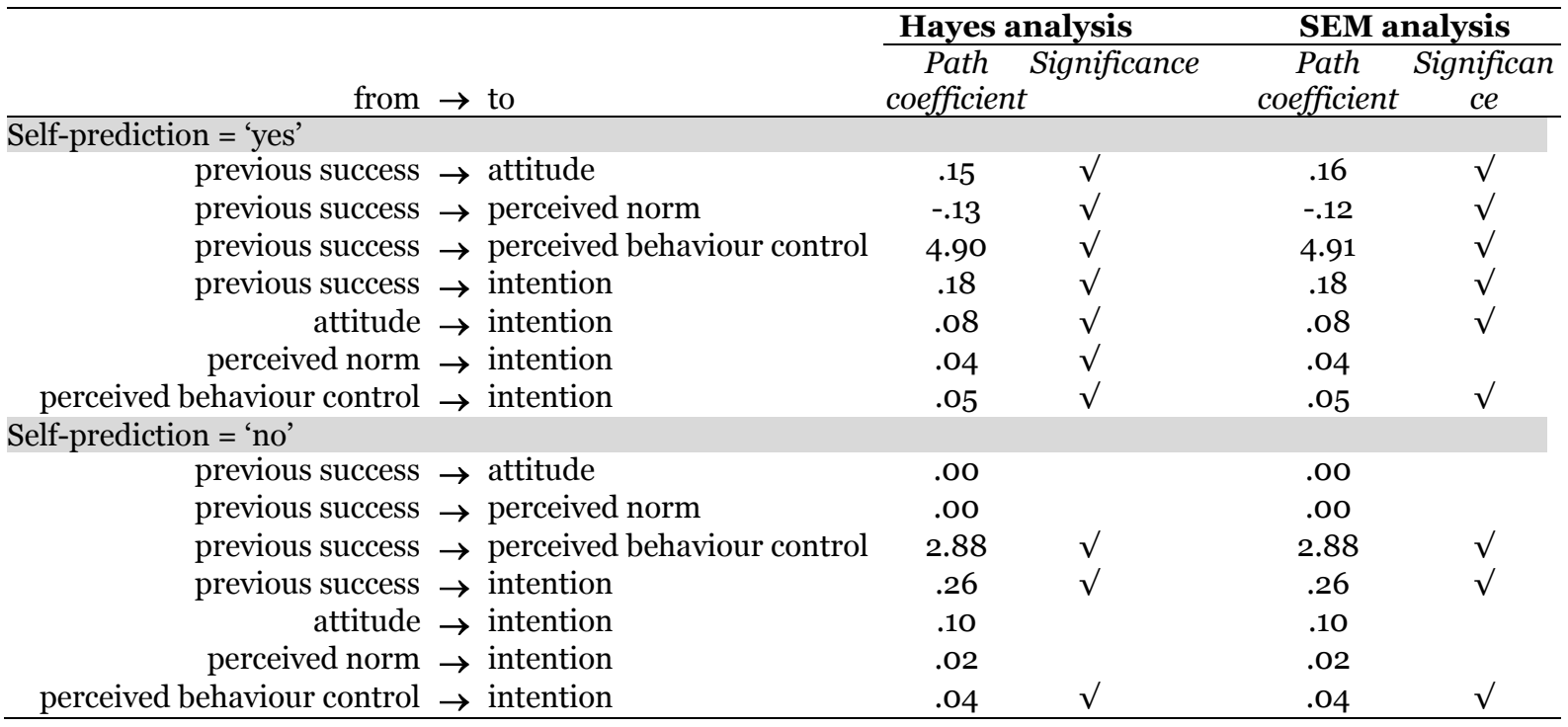

\section{Conclusions and Discussion}

The main research question addressed in this study was: "Do perceptions of success in using DLMs regularly (i.e., several times a week) during classes in the past year, strengthen (or weaken) teachers' behavioural intentions to use DLMs again on a regular basis in the coming year?" To answer this research question, teachers' flows were first analysed using crosstabs / multinomial logistic regression. These flows designated the relationship between teachers 1) who had perceived some degree of success of actual using DLMs regularly during classes in the past year or 2) who had no intention at all in the past year to use DLMs, and how they flow into three ordered categories of different strengths of the behavioural intention to use DLMs regularly in the coming year. The unit of analysis was either the group of teachers (the analysis used crosstabs) or the individual teacher (the analysis used multinomial logistic regression). The variable self-prediction was used to distinguish the group of teachers that predicted that they are going to use DLMs on a regular basis from the group of teachers that predicted they were not going to use DLMs on a regular basis in the coming year. The results indicated that teachers who had experienced various degrees of success using DLMs in the past school year showed stronger (for the crosstabs analysis) or corresponding (for the multinomial logistic regression) behavioural intentions to use DLMs regularly again for the case that their self-prediction was positive. This also applied to teachers who had no intention at all to use DLM regularly in the past year; they now had a moderate (for the crosstabs analysis) or a no to weak intention (for the multinomial logistic regression) to use DLMs regularly in the coming year. For the case that the self-prediction was negative, teachers had accordingly a much weaker intention to use DLMs regularly again in the coming year. 
That is, for the crosstabs analysis, the teacher flows were in accordance with the expectations, and for the multinomial logistic regression, these flows were weaker than expected. Furthermore, the multinomial logistic regression, but not the crosstabs, showed for both cases (self-prediction is "yes" and "no") deviating behavioural intentions of what was expected, but these were in the minority. As a result, it was concluded that hypotheses H1a, H1b, and H1c were confirmed.

After the determination of the teachers flows, the effect of perceived success on the behavioural intention to use DLMs regularly again in the coming year was investigated using the Reasoned Action Approach. It was also investigated whether this effect was mediated by attitude, perceived norm, and perceived behavioural control, and whether a direct effect could be determined. The analyses with the Hayes (2013) process method indicated that for the case where the self-prediction was positive, both attitude and perceived norm mediated the effect of the perceived success on the behavioural intention but that these effects diminished when self-prediction was negative. The results of the SEM analysis confirmed this conclusion. With respect to attitude, this result was somewhat surprising. Indeed, previous research (e.g., Kreijns, Van Acker, Vermeulen, \& van Buuren, 2013)) has indicated that attitude is a crucial variable in the formation of a behavioural intention under different conditions. We belief that our choice for using a proxy for attitude did underrepresent the attitude construct and this caused the surprising results. With respect to perceived norm, the result was less surprising, as much research (e.g., Kreijns, Vermeulen, Van Acker, \& van Buuren, 2014) has shown an unimportant role of perceived norm when it comes to the forming of a behavioural intention. A direct effect was also seen for both cases of a positive and negative self-prediction. The results of the SEM analysis further indicated that perceived success explained .44 and .31 of the variance in behavioural intention for respectively a positive and negative self-prediction. Based on these results, it was concluded that the hypotheses H2a, and $\mathrm{H} 2 \mathrm{~b}$, were confirmed for the case of a positive self-prediction but not for the case of a negative selfprediction. Hypotheses H2c was confirmed for both cases of self-prediction.

In conclusion, although individual teachers did not show a stronger intention when teachers perceived success in using DLMs regularly in the past school year, they did, however, maintain a behavioural intention that was in accordance with the degree of perceived success for the case of a positive selfprediction. But in the case of a negative self-prediction teacher, results showed a weaker behavioural intention to use DLMs again on a regular basis. However, there were teachers who showed a behavioural intention that was unexpected.

The current research has some limitations. Using a proxy for attitude was possibly underrepresenting the attitude construct. Our future research, therefore, will use the common way to measure attitude; Fishbein \& Ajzen (2010) suggested to use bipolar scales for measuring attitude. Another limitation concerns the population of teachers: only Dutch teachers participated in the research. Teachers' use of ICT, and in particular, DLMs is not a case that only matters the Dutch situation but it is a concern that is shared with all other countries over the world. Moreover, situations may differ from country to country (Kozma, 2003). Finally, the current research was cross-sectional, and consequently, it is not possible to determine the causal sequence. Longitudinal research in the future should give more insight in the causality in the relationships between perceived success, self-prediction, and behavioural intention.

For the educational practice, this research stipulated the importance of teachers to get a chance to experience success with the use of DLMs during their lessons. School leaders, therefore, should support and encourage the use of DLMs by teachers and take care of their ICT professional development. 
Professional development programmes should guide the experiences with DLMs in such a way that success experience is more guaranteed. For example, scaffolding the teachers' use of DLMs from simple to more complex. School leaders should also be aware that teachers experimenting and using DLMs will not become demotivated due to an insufficient and unreliable ICT infrastructure; unsuccessful experiences lead to no or weak intentions. Furthermore, school leaders should take care that there is a balance in the workload of teachers, so that competing task demands will not severely limit teachers' decisions to use DLMs in the near future, which is reflected in their self-prediction. Even the most motivated and skilful teachers may not use DLMs if there are too many other tasks that have to be done under time pressure. By encouraging DLMs use in a supporting environment more perceived success can be expected, with the consequence of more DLMs use and again more perceived success. Getting this process started, however, is a careful designed process which actually begins at the teacher training institutions. These institutions are responsible that DLM use become part of the teachers' repertoire.

Only when all these considerations are taken into account, will we see teachers' willingness to use DLMs on a regular basis grow.

\section{References}

Ajzen, I. (1991). The theory of planned behaviour. Organizational Behaviour and Human Decision Processes, 5o, 179-211.

Armitage, C. J., \& Conner, M. (2001). Efficacy of the theory of planned behaviour: A meta-analytic review. British Journal of Social Psychology, 40, 471-499.

Bandura, A. (1986). The explanatory and predictive scope of self-efficacy theory. Journal of Clinical and Social Psychology, 4, 359-373.

Fishbein, M., \& Ajzen, I. (2010). Predicting and changing behaviour: The reasoned action approach. New York: Psychology Press (Taylor \& Francis)

Hagger, M. S., Chatzisarantis, N., \& Biddle, S. J. H. (2001). The influence of self-efficacy and past behaviour on the physical activity intentions of young people. Journal of Sport Sciences, 19, $711-725$.

Hayes, A. F. (2012). PROCESS: A versatile computational tool for observed variable mediation, moderation, and conditional process modeling [White paper]. Retrieved from http://www.afhayes.com/

Hayes, A. F. (2013). An introduction to mediation, moderation, and conditional process analysis: A regression-based approach. New York: Guilford Press.

Kozma, R. (2003). ICT and educational change: A global phenomenon. In R. Kozma (Ed.), Technology, innovation and educational change: A global perspective (pp. 1-19). Eugene, OR: Information Society for Technology in Education. 
Kreijns, K., Van Acker, F., Vermeulen, M., \& van Buuren (2013). What stimulates teachers to integrate ICT in their pedagogical practices? The use of digital learning materials in education. Computers in Human Behaviour, 29(1), 217-225.

Kreijns, K., Vermeulen, M., Van Acker, F., \& van Buuren, H. (2014). Predicting teachers' use of digital learning materials: Combining self-determination theory and the integrative model of behaviour prediction. European Journal of Teacher Education, 37(4).

Ouellette, J. A., \& Wood, W. (1998). Habit and intention in everyday life: The multiple processes by which past behaviour predicts future behaviour. Psychological Bulletin, 124(1), 54-74.

Preacher, K. J., \& Hayes, A. F. (2008). Asymptotic and resampling strategies for assessing and comparing indirect effects in multiple mediator models. Behaviour Research Methods, 40 , 879-891.

Tondeur, J., Valcke, M., \& van Braak, J. (2008). A multidimensional approach to determinants of computer use in primary education: Teacher and school characteristics. Journal of Computer Assisted Learning, 24, 494-506.

Vrasidas, C. (2015). The rhetoric of reform and teachers' use of ICT. British Journal of Educational Technology, 46(2), 370-380.

\section{Athabasca}

University

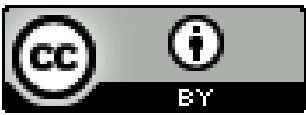

